\title{
Eosinophilic Esophagitis-More than Two Decades of Progress
}

\author{
Erik Rahimi and Atilla Ertan* \\ Ertan Digestive Disease Center of Excellence, Memorial Hermann Hospital and Division of Gastroenterology, Hepatology, and Nutrition, Department of \\ Internal Medicine, University of Texas Health Science Center at Houston, Texas, USA
}

Received: February 02, 2015; Accepted: March 01, 2015; Published: March 17, 2015

*Corresponding author: Atilla Ertan, MD, FACP, AGAF, MACG, Director of the Ertan Digestive Disease Center and GI Center of Excellence, MHPB-Texas Medical Center, Professor at the University of Texas Medical School Gastroenterology \& Hepatology Division, Phone: 713-704-5928, -3435, \& -3450; Fax: 713-704-3485; E-mail: atilla.ertan@uth.tmc.edu

\begin{abstract}
Eosinophilic Esophagitis (EoE) is a chronic immune/antigenmediated disease recognized as a distinctive entity more than 2 decades ago. There has been an increasing prevalence in both children and adults since then. Food and/or environmental allergens trigger a T-helper 2 (Th2) cell-mediated immune response in the esophagus leading to an inflammatory response. EoE has a progressive course from inflammation to fibrostenotic disease, and early diagnosis and treatment are essential. EoE has no distinct pathognomonic findings, however diagnosis is based on patient symptoms of esophageal dysfunction, esophageal biopsies usually $>15$ eosinophils/high power field and exclusion of other causes of esophageal eosinophilia such as gastroesophageal reflux disease (GERD) and proton pump inhibitor responsive esophageal eosinophilia (PPI-REE). The mainstay of treatment involves PPI therapy, swallowed inhaled steroids, tablet or viscous budesonide, elimination of dietary triggers, and esophageal dilation as needed. Relapse rate is high and continuing maintenance therapy is beneficial and recommended. Further studies are needed for long term outcome with continued diet elimination, steroids, and/ or other treatment modalities.
\end{abstract}

Keywords: Eosinophilic Esophagitis; EOE; Eosinophils; Reflux; Epidemiology; Steroid; Diet; Dilation

\section{Introduction}

Eosinophilic Esophagitis (EoE) is a clinicopathologic disease that affects both children and adults. EoE is defined as a chronic, immune/antigen-mediated esophageal disease characterized clinically by symptoms related to esophageal dysfunction and histologically by eosinophil-predominant inflammation [1]. The presence of eosinophils in the esophagus, known as esophageal eosinophilia, does not alone confer diagnosis of EoE. Along with a myriad of other diseases, gastroesophageal reflux disease (GERD) and proton pump inhibitor-responsive esophageal eosinophilia (PPI-REE) are common entities that have esophageal eosinophilia [2,3]. Diagnostic guidelines for EoE were first created at the first International Gastrointestinal Eosinophil Research Symposium in 2007, and updated in 2011. Diagnostic criteria include symptoms related to esophageal dysfunction, eosinophilpredominant inflammation on esophageal biopsies from the distal and proximal esophagus (peak value of $\geq 15$ eosinophils per high-power field (eos /HPF)), eosinophilia that is isolated to the esophagus and persists after a PPI trial, exclusion of secondary causes of esophageal eosinophilia, and a response to therapy [4]. In this review we focus on epidemiology, pathogenesis, clinical and histopathologic findings, and treatment for EoE.

\section{Epidemiology}

EoE was first described in 1978 and in the 1990s was increasingly recognized as a distinctive entity [5]. The clinicopathologic syndrome was also found to be associated with allergies and a hypersensitivity to certain dietary proteins [6,7]. The incidence of EoE appears to be increasing, likely from a combination of increasing associated allergic diseases and recognition of EoE as a specific entity [8]. EoE affects both children and adults, with a predilection for male over female patients of about $3: 1$. Estimates of prevalence in children vary in range from 7.3 to 43 per 100,000 [9-11]. Estimates of incidence and prevalence in the adult population vary as well. A study in 2009, by Prasad et al, evaluated 3 decades (1976-2005) of patients with EoE in Olmsted County, Minnesota. The incidence increased significantly with time from 0.35 per 100,000 personyears during $1991-1995$ to 9.45 per 100,000 person-years during 2001-2005. The prevalence rate was 55.0 per 100,000 persons, with a tendency of more patients diagnosed in the late summer/ fall [12]. Epidemiologic studies from Olten County, Switzerland between 1989-2009, also showed a marked increase in EoE incidence rate from 2004 to 2009 of 4.4 to 7.4 per 100,000 inhabitants per year, respectively [13]. A study in 2014, by Ally et al, determined the prevalence of EoE using the U.S. military health care system database to be 9.5 per 100,000 for adults, with a predominance in Caucasians versus African Americans (18.1 vs. $5.2 / 100,000$, OR 3.47 [ $95 \%$ CI 2.40-5.03]). The mean age at diagnosis was in middle age males (age 34), with a peak age distribution between 30 and 50 years. Furthermore, there was an increased prevalence in Northern states compared to Southern states (10.9 vs. $7.2 / 100,000$, respectively, $P<0.05$ ) [14]. Another 2014 population based study using an insurance registry from 2008-2011 showed an estimated period prevalence of EoE to 
be $58.9 / 100,000$ persons in adults and $56.7 / 100,000$ persons overall, which translates into approximately 152,152 cases in the U.S. [15]. Compared to prior studies this estimated prevalence is likely more precise as it is based on the significantly larger sample size of $11,569,217$ individuals. Also more importantly is that $75 \%$ of the cases were adults, reflecting that EoE is predominantly a disease of adult patients [16].

\section{Pathogenesis}

Along with food allergies, aeroallergens have been implicated in the pathogenesis of EoE. There is conflicting data whether seasonal variation exists in the diagnoses of EoE. Moawad et al in 2009 , identified $33.0 \%(\mathrm{P}=0.023)$ of $127 \mathrm{EoE}$ patients to be diagnosed in the spring, while in the winter the least percentage of EoE patients were diagnosed (16\%; P $=0.010)$. Correlation was also seen between mean grass pollen count which peaked in the spring time and the percent in rise of EoE cases $(\mathrm{P}<0.01)$. In the summer months asthmatic EoE patients were more likely to be diagnosed, compared to EoE patients with food allergy that did not have a peaked season [17]. Another study in 2009 by Almansa et al, found that more cases of EoE were diagnosed in April and May, compared to other months $(\mathrm{P}<0.001)$. In the same study $61 \%$ of the original cohort had a history of allergies [18]. In comparison, a 2013 study of children diagnosed with EoE showed there was no significant association with different seasons and EoE diagnosis $(\mathrm{P}=0.2035)$ [19]. A more recent study in 2014 by Elias et al also showed a different trend with peak periods of diagnosis for symptomatic esophageal eosinophilia in December-January (11-13\%), and less in May-June (11 - 9\%) $(p=0.014)$ [20]. Along with aeroallergens, food antigenic triggers exist. These include milk and wheat, which are the most common triggers, and egg, soy, meats, grains, peanuts/tree nuts, fish, and shellfish [21]. It is believed that the mechanism in which EoE occurs is by food or environmental allergens contacting a possible leaky esophageal epithelium and triggering a T-helper 2 (Th2) cell-mediated immune response (involving interleukin [IL]-4, IL5, IL-9 and IL-13). This response stimulates the epithelium to produce eotaxin-3, a potent chemokine that recruits eosinophils, which promotes local inflammation, injury, and tissue remodeling via increased expression of transforming growth factor (TGF)- $\beta 1$ leading to smooth muscle dysfunction [22-24].

\section{Clinical and Histopathologic Findings}

Clinical manifestations of EoE vary and thus far there is no pathognomonic feature for the disease. EoE can occur in any age, race, and gender, however the classic presentation is an atopic, non-hispanic male that presents in childhood or the $3^{\text {rd }}$ to $4^{\text {th }}$ decade of life [25]. Typical feeding difficulties in infants and toddlers, includes oral aversion, food refusal, vomiting, and poor weight gain. Improvement in symptoms occurs in $73 \%$ after treatment [26]. Preschool and school aged children may have abdominal pain and vomiting, while older children generally have dysphagia [27]. In adults clinical manifestations mainly involve dysphagia (70.1\%), GERD/ heartburn (27.1\%), and abdominal pain (13.1\%) [28] Identifying EoE from GERD is important.
Markowitz et al in 2003, found that $14.7 \%$ of 346 patients with chronic GERD symptoms and eosinophils on esophageal biopsy ultimately had a diagnosis of EoE [29]. A serious symptom of a food bolus impaction can also occur in EoE, and was noted to range from $12 \%$ to $42 \%[30,31]$. It is important to ask patients about avoidance of specific foods, thoroughness of chewing, and other dietary modifications that reduce symptoms of dysphagia. Further associated clinical symptoms of EoE are those of atopic diathesis. These include atopy, typically seen in children up to $50-80 \%$, allergic rhinitis, asthma, eczema, family history of atopy, elevated serum IgE level, peripheral blood eosinophilia, and positive allergy testing [32]. However these findings alone are not predictive of severity of eosinophilia [33]. When EoE is suspected based on history and clinical manifestations an upper endoscopy is warranted to further evaluate and to obtain esophageal biopsies. Endoscopic findings of EoE include the classic esophageal concentric rings (Figure 1) that can be fixed or transient, called felinization. Strictures form in patients with chronic inflammation and fibrosis. Further findings include small (narrow) caliber esophagus, longitudinal furrows (Figure 2), white plaques / exudates, pallor, decreased vasculature, edema, and crêpe-paper mucosa, which is fragile esophageal mucosa that tears upon passing of the endoscope $[34,35]$. Interobserver agreement of endoscopic findings of EoE was shown to be fair to good when using white light and narrow band imaging (NBI) to identify rings and furrows, however it was poor for identifying plaques and intraobserver agreement varied greatly [36]. A severity score for the assessment of EoE disease activity was validated with good interobserver agreement. This score is the EoE endoscopic reference score (EREFS). The acronym reflects the major components of the score: exudates, rings, edema, furrows, and strictures. The minor component is crepe paper esophagus [37]. In some studies, including a meta-analysis of 4,768 patients with EoE, the esophagus was shown to be normal in $10 \%-17 \%$ of patients undergoing EGD. Furthermore, the metaanalysis showed a low sensitivity and variable predictive values

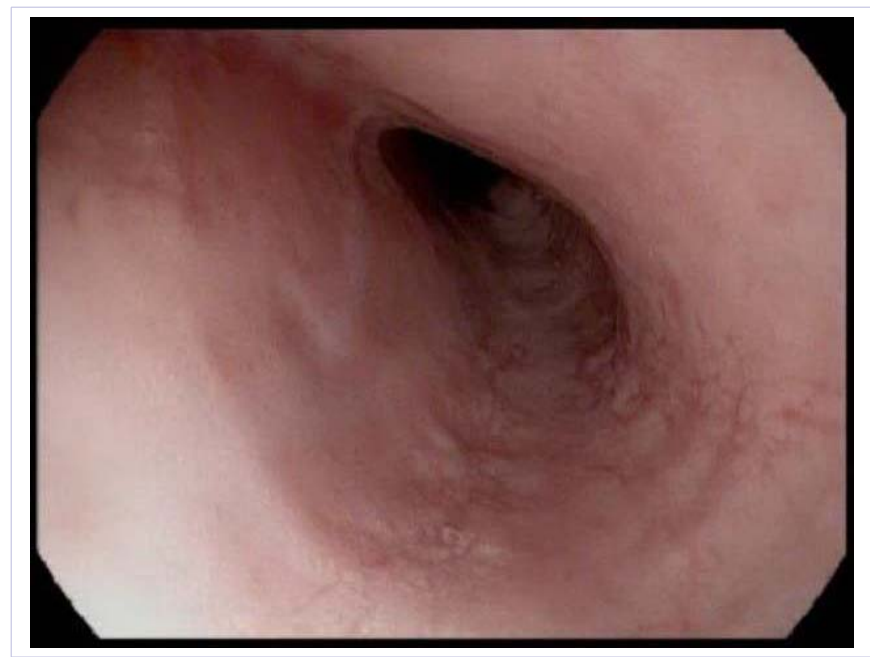

Figure 1: Concentric rings in the mid-esophagus. 


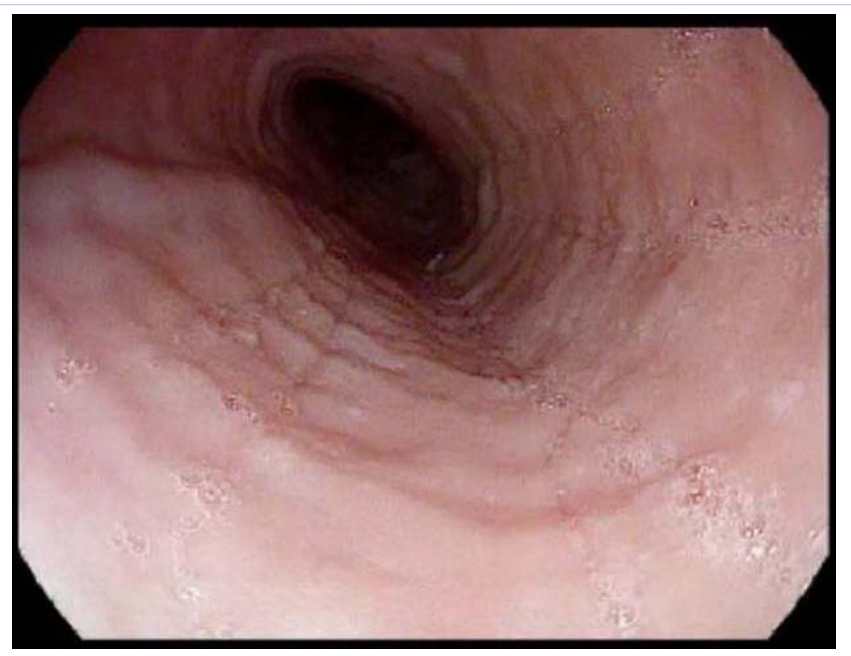

Figure 2: Concentric rings in the mid-esophagus.

for endoscopic findings to diagnose EoE [38,39]. Endoscopic characteristics, therefore, alone are not diagnostic of EoE and biopsies are warranted in cases with and without endoscopic findings. It is recommended that $2-4$ biopsies be obtained from a minimum of 2 different locations in the esophagus, usually the distal and proximal esophagus. Also abnormal findings in the esophagus should be biopsied [4]. The distal esophagus has been shown to have a higher number of eosinophils, and is an important location for biopsies to be obtained. Furthermore, obtaining $\geq 5$ biopsies compared to 1 biopsy increases the sensitivity to $100 \%$ from $55 \%$, respectively [40]. Histopathologic features must be interpreted in conjunction with the patient's clinical information. Consensus recommendations report that esophageal biopsy with $\geq 15$ eosinophils in at least one microscopy high-power field (HPF) is consistent, but not diagnostic in of itself for EoE [1]. Other publications have given a range of histopathological cut-off points from 15 to 25 eos /HPF. Even if there was a common cutpoint for eosinophil count, different HPF sizes were used resulting in variation in eosinophil density (eos / $\mathrm{mm} \mathrm{2}$ ). Also there was a remarkable six-fold difference between HPF sizes being used [41]. Because of HPF variability, reporting eosinophil density in eosinophils per mm2 may eliminate this inconsistency. This technique showed excellent inter- and intra-observer reliability for determining eosinophil densities and it also valid when compared with counts obtained from traditional glass slides. However there is no standard eosinophil density being used in diagnostic guidelines [42]. Distinction of EoEversus GERD induced esophageal eosinophilia is frequently not possible based on histology alone, although there are further ancillary findings that are more suggestive of EoE. Findings of degranulated eosinophils, eosinophilic microabscesses, diffuse intraepithelial distribution of eosinophils, basal cell hyperplasia, lamina propria fibrosis, and elongated lamina propria papillae are more common in EoE [43]. Again, none of these findings are pathognomonic for EoE, and findings of esophageal eosinophilia does not confer a diagnosis of EoE. Secondary causes of esophageal eosinophilia need to be considered. The differential diagnosis of esophageal eosinophilia includes the most common GERD and PPI-REE, along with celiac disease, infection, eosinophilic gastrointestinal diseases, hypereosinophilic syndrome, achalasia, drug hypersensitivity, vasculitis, pemphigus, connective tissue disease, graft versus host disease, and post-radiofrequency ablation $[1,4,44]$.

\section{Therapy}

When esophageal eosinophilia is present the role of PPI therapy is important to differentiate EoE from non-EoE patients. High dose PPI with anti-reflux measures are useful in treating patients with esophageal eosinophilia secondary to GERD, PPIREE, and EoE $[45,46]$. In patients found to have esophageal eosinophilia it is recommended to give a PPI once or twice daily for 8 to 12 weeks in adults and $1 \mathrm{mg} / \mathrm{kg}$ per dose, twice daily for 8 to 12 weeks in children. If there is a lack of clinicopathologic response to PPI treatment in patients with symptoms of EoE and isolated esophageal eosinophilia then the findings are consistent with a diagnosis of EoE [1]. Therapeutic strategies are targeted at the pathogenesis of EoE. The treatment approaches for EoE involves drugs and dietary changes to target the inflammatory component of the disease, and if needed endoscopic intervention with dilation for fibrotic changes due to remodeling. Drugs and diet, alone or in combination, are typical first-line agents. Currently the medications used in treating EoE are off-label use, as no drugs have been approved by the Food and Drug Administration for treatment of EoE [35]. As per recommendations, the endpoints in treatment of EoE include improvements in symptoms and esophageal eosinophilic inflammation [4]. Acid suppression medications and corticosteroids are the major groups of drugs used for the treatment of EoE. Further trials are underway for alternative medications in EoE therapy.

\section{Proton Pump Inhibitors}

The use of PPI for acid suppression can lead to a symptomatic response. Patients with EoE were shown to be hypersensitive to acid, and therefore reflux likely plays a role in causation of symptoms [47]. In a study comparing PPI therapy to topical steroids in EoE adults with dysphagia, both groups had similar improvement in symptoms and eosinophilic infiltration regardless of underlying concomitant GERD, however this study was limited by a small cohort [48].

\section{Steroids}

In order to achieve both clinical and histologic improvement the use of corticosteroids, via topical or systemic steroids, is needed. As per consensus recommendations and per our experience, first line pharmacologic therapy for EoE involves topical steroids, such as swallowed fluticasone or budesonide, for an initial duration of 8 weeks [4]. The use of systemic steroids for treatment of EoE was described in the 1990s with both improvement in clinical symptoms and reduction of eosinophils from esophageal biopsies. However, recurrence of symptoms was common after cessation of steroid therapy with only $50 \%$ remaining asymptomatic $[49,50]$. Due to high side effect profile 
from systemic steroids, such as hyperphagia, weight gain, edema, cushingoid features, and hyperglycemia the use of topical steroids, such as swallowed inhaled steroids or budesonide, has been implemented. In a study comparing systemic steroids versus topical steroids the histologic response was greater in systemic steroids $(\mathrm{P}=.0440)$. However the lack of long-term benefit from systemic steroids and up to $40 \%$ of patients having side effects, topical steroids are favored. Systemic steroids, such as methylprednisolone or prednisone, may still be given in patients with poor response to topical steroids or who require a rapid improvement in symptoms for severe dysphagia, hospitalization, and weight loss $[1,4,51]$.

In 1998, Faubion et al, was the first to use topical steroids by swallowing, rather than inhaling, an inhaled fluticasone or beclomethasone in 4 pediatric patients with EoE. Improvement was shown to occur about 1 week after using this regimen [52]. Since then several observational studies and randomized controlled trials have shown improved symptoms and / or histologic response using topical steroids (Table 1). Teitelbaum et al in 2002 treated 9 EoE pediatric patients with fluticasone who did not respond to dietary restriction. These patients showed improved symptoms and also significant change in follow-up esophageal eosinophilia count [53]. In a 2006 RCT of 21 EoE pediatric patients that were treated with fluticasone, $50 \%$ achieved histologic remission defined as a peak eosinophil count of $<1$ eosinophil / HPF, versus only $9 \%$ of patients receiving placebo $(P=0.047)$ [54]. Similar findings of symptomatic improvement were seen in adult patients receiving fluticasone [55]. A study by Remedios et al treated EoE patients with fluticasone, including a subset of patients with concomitant GERD. Patients overall responded both clinically and histologically to fluticasone [31]. A study by Lucendo et al in 2007 treated EoE patients with findings of abnormal esophageal caliber and abnormal mucosa. After treatment with fluticasone, the esophagus showed a normal caliber in $97 \%$ of patients, and $63 \%$ of patients had normal mucosa [56]. In a double blind RCT by Alexander et al evaluated 30 patients with EoE treated with fluticasone versus placebo. Histologic response was seen in the topical steroid group, however dysphagia was not significantly reduced in the treatment group (63\% fluticasone group and $47 \%$ placebo group; $(P=0.49)$ [57]. In a study by Butz et al in 2014 , recommended that patients being treated with high dose fluticasone $(1760 \mathrm{mcg})$ should be followed up in 3 months for response and can either have dose reduction to $880 \mathrm{mcg}$ or continue with high dose for another 3 months [58]. Due to the difficulty aerosolized corticosteroids may be for young children to ingest, Aceves et al used viscous budesonide to treat pediatric patients with EoE with significant reduction in symptoms and histology $[59,60]$. Further studies including RCTs by Straumann et al in 2010 and Dohil et al in 2010, both showed clinical and histologic improvement after nebulized to liquid budesonide or viscous budesonide was given [61,62]. A study by Dellon et al, in 2012, compared viscous budesonide to nebulized steroid therapy for EoE. Histologic improvement was significantly better in the viscous budesonide group, favoring this therapy [63].
We use $3 \mathrm{mg}$ tablet or preferentially liquid budesonide before bedtime for 6-8 weeks. Advanced cases may need to be treated for a longer period of time with maintenance therapy and a GI hypoallergenic diet. Although, an indefinite GI hypoallergenic diet is recommended in patients with EoE, no definitive studies are available for a possible maintenance therapy in this chronic and usually progressive disease.

\section{Biological agents}

Interleukin-5 (IL-5) has been shown to induce eosinophil trafficking in the esophagus. Two medications that are antibodies against IL-5, mepolizumab and reslizumab, have been assessed for the management of pediatric EoE cases. An initial open labeled trial of 4 patients in 2006 receiving mepolizumab, showed both a reduced esophageal eosinophilic count and improvement in symptoms. Two larger trials including a RCT of 59 children receiving mepolizumab, showed a decrease in eosinophilic count, however not a significant change in symptoms [64-66]. In a 2012 study, 226 children and adolescents with EoE were given reslizumab with significant improvement in intraepithelial esophageal eosinophil counts. However, this improvement in eosinophil count was not accompanied by significant differences in clinical symptoms and quality of life compared to the placebo group [67]. Immunoglobulin E (IgE) plays a role in the pathogenesis of EoE. Omalizumab, an antiIgE antibody, was assessed in the treatment of EoE. In a study of 2 patients with EoE, omalizumab was used to improve food intolerance in this patients. Although symptoms improved there was no improvement in histologic response [68]. In 2011, a RCT involving 30 patients with EoE receiving omalizumab showed no clinical and histologic improvement compared to placebo [69]. Along with a Th2 cell-mediated immune response, inhibitor of tumor necrosis factor-alfa (TNF- $\alpha$ ) has been shown to be upregulated and highly expressed in epithelial cells of the esophagus in patients with active EoE [70]. Infliximab, a potent inhibitor of TNF- $\alpha$, was used in an open-labeled, non-randomized trial of 3 adults with severe, corticosteroid-dependent EoE. This treatment modality did not induce a resolution of the eosinophilic tissue infiltration, or improvement in symptoms [71].

\section{Immunomodulators}

In a case series of 3 patients with EoE dependent on steroids, were treated with either azathioprine (AZA) or 6-mercaptopurine. The results showed a positive response with clinical and histological remission that was maintained during the follow-up period of 3-8 years [72]. Currently there are no further studies using this type of treatment modality for steroid dependent EoE.

\section{Dietary treatment}

Food allergens have been implicated in the pathophysiology of EoE, therefore removal of allergic dietary antigens is also a mainstay of EoE therapy. Dietary treatment comprises of elemental and/ or restrictive-elimination diets. Elemental diets include amino-acids, basic carbohydrates and medium 
Table 1: Therapeutic studies for EoE using swallowed inhaled steroids or viscous budesonide.

\begin{tabular}{|c|c|c|c|c|c|c|c|c|c|c|c|}
\hline \multirow{3}{*}{\begin{tabular}{|c|}
$\begin{array}{c}\text { Author/ } \\
\text { Year of } \\
\text { Study }\end{array}$ \\
\\
$\begin{array}{c}\text { Teitel- } \\
\text { baum }^{53}\end{array}$ \\
\end{tabular}} & \multirow{3}{*}{\begin{tabular}{|c|}
$\begin{array}{c}\text { Type of study } \\
\text { / Study Dura- } \\
\text { tion }\end{array}$ \\
Prospective
\end{tabular}} & \multirow{3}{*}{$\begin{array}{c}\text { Age group } \\
\text { Peds } \\
\end{array}$} & \multirow{3}{*}{\begin{tabular}{|c|}
$\begin{array}{c}N= \\
\text { cohort } \\
\text { (Male) }\end{array}$ \\
\\
$19(14)$
\end{tabular}} & \multirow{3}{*}{$\begin{array}{c}\begin{array}{c}\# \\
\text { Treat- } \\
\text { ed }\end{array} \\
\\
9 \\
\end{array}$} & \multirow{3}{*}{$\begin{array}{c}\text { Thera- } \\
\text { py } \\
\\
\text { FP } \\
\end{array}$} & \multirow{3}{*}{\begin{tabular}{|l|} 
Duration \\
8 weeks \\
\end{tabular}} & \multirow{3}{*}{$\begin{array}{c}\text { Symptoms } \\
\text { improved }\end{array}$} & \multicolumn{2}{|c|}{$\begin{array}{c}\text { Pre Therapy Eos/ } \\
\text { HPF }\end{array}$} & \multirow{2}{*}{$\begin{array}{l}\text { Post Therapy } \\
\text { Eos/HPF } \\
\text { / HPF }\end{array}$} & \multirow{3}{*}{$\begin{array}{l}\text { P-value } \\
\mathrm{p}=0.001\end{array}$} \\
\hline & & & & & & & & \multirow{2}{*}{\begin{tabular}{|c|}
$\begin{array}{c}\text { Esophagus } \\
\text { (location) }\end{array}$ \\
Proximal \\
\end{tabular}} & Eos / HPF & & \\
\hline & & & & & & & & & $22.5 \pm 4.9$ & $2.8 \pm 2.4$ & \\
\hline 2002 & $1998-2001$ & & & & & & & Distal & $23.0 \pm 2.7$ & $2.7 \pm 1.4$ & $\mathrm{p}=0.001$ \\
\hline Arora $^{55}$ & Prospective & Adults & $21(17)$ & 21 & $\mathrm{FP}$ & 6 weeks & Yes & Proximal & $\mathrm{N} / \mathrm{A}$ & $\mathrm{N} / \mathrm{A}$ & N/A \\
\hline 2003 & 1999-2001 & & & & & & & Distal & $>50$ & $\mathrm{~N} / \mathrm{A}$ & N/A \\
\hline Konikoff ${ }^{54}$ & RCT & Peds & $36(17)$ & 21 & FP & 3 months & Yes & Proximal & $69.4 \pm 14.5$ & $35.2 \pm 12.6$ & $\mathrm{p}=0.05$ \\
\hline 2006 & $2003-2005$ & & & & & & & Distal & $82.2 \pm 11.7$ & $45.7 \pm 13.6$ & $\mathrm{p}=0.07$ \\
\hline Remedios $^{31}$ & Prospective & Adult & $26(18)$ & 19 & FP & 4 weeks & Yes & Proximal & 24.98 & 4.46 & $\mathrm{p}<0.0004$ \\
\hline 2006 & $2002-2003$ & & & & & & & Distal & 39.34 & 3.81 & $\mathrm{p}<0.0001$ \\
\hline Lucendo $^{56}$ & Prospective & Adult & $30(27)$ & 27 & FP & 3 months & Yes & & $\mathrm{N} / \mathrm{A}$ & $\mathrm{N} / \mathrm{A}$ & \\
\hline 2007 & 2002-2005 & & & & & & & & & & \\
\hline Aceves $^{60}$ & Retrospective & Peds & $20(16)$ & 20 & VB & 3 months & Yes & Proximal & 43 & 2 & $\mathrm{p}<0.0001$ \\
\hline 2007 & 2007 & & & & & & & Distal & 80 & 9 & \\
\hline Straumann ${ }^{61}$ & RCT & \multirow{2}{*}{$\begin{array}{c}\text { Adolescent/ } \\
\text { Adult }\end{array}$} & $36(31)$ & 18 & SIB & 15 days & Yes & Overall & 68.2 & 5.5 & $\mathrm{p}<0.0001$ \\
\hline 2010 & $2006-2007$ & & & & & & & & & & \\
\hline Dohil $^{62}$ & RCT & Peds & $24(20)$ & 15 & VB & 3 months & Yes & Overall & 66.7 & 4.8 & $\mathrm{p}<0.0001$ \\
\hline 2010 & 2008-2009 & & & & & & & & & & \\
\hline Dellon $^{63}$ & RCT & Adults & $25(15)$ & 11 & \multirow{2}{*}{$\begin{array}{l}\text { VB vs } \\
\text { SIB }\end{array}$} & 8 weeks & Yes (VB) & Overall & 89 & 11 & $\mathrm{p}=0.02$ \\
\hline 2012 & $\mathrm{~N} / \mathrm{A}$ & & & & & & Yes (SIB) & Overall & 101 & 89 & \\
\hline Alexander ${ }^{57}$ & RCT & Adult & $42(30)$ & 21 & FP & 6 weeks & No & Peak (Eos) & 40 & 2 & $\mathrm{p}<0.001$ \\
\hline 2012 & $2005-2009$ & & & & & & & & & & \\
\hline Butz $^{58}$ & RCT & Adult / Peds & $42(35)$ & 28 & FP & 6 months & Yes & Proximal & 53.5 & $\begin{array}{l}>90 \% \text { de- } \\
\text { crease }\end{array}$ & $\mathrm{p}=0.0001$ \\
\hline 2014 & 2006 & & & & & & Yes & Distal & 56.3 & $\begin{array}{c}>90 \% \text { de- } \\
\text { crease }\end{array}$ & $\mathrm{p}=0.0001$ \\
\hline
\end{tabular}

FP = Fluticasone Propionate $;$ Eos = Eosinophils; HPF = high power field RCT = randomized control trial; VB = Viscous Budesonide; SIB = Swallowed Inhaled Budesonide

chain triglycerides. The use of an elemental diet has shown to significantly improve symptoms in children and reduce the number of esophageal eosinophils [29]. Elemental diet has also been shown to be superior to elimination diets. In a study comparing elemental diet to elimination diets remission occurred in $96 \%, 81 \%$, and $65 \%$ of patients on elemental diet, 6-food elimination diet, and directed diets, respectively [73]. In a recent meta-analysis involving 1,317 patients from 33 studies effectiveness of elemental diet was seen $90.8 \%$ of cases, 6-food elimination diet was $72.1 \%$ effective, and allergy test result-directed food elimination was $45.5 \%$ effective [74]. The disadvantages of elemental diets involve poor palatability, possible need for enteral feeding tubes, patient compliance, and cost [35]. Elimination diets can be based on direct (allergy testing) or non-direct (empiric) elimination methods. Eliminating foods in children with EoE based on allergy testing with both skin prick and atopy patch testing showed a $77 \%$ improvement in symptoms and esophageal inflammation on follow-up. Egg, milk, soy, corn and wheat were identified most frequently between the groups as food allergens [75]. However the use of skin prick testing alone only predicted $13 \%$ of foods associated with EoE [76]. Food allergy testing may be more useful in pediatric patients with EoE than the adult population. Food sensitization and allergic responses are usually seen in children as opposed to adults who have aeroallergen allergies [77]. Six-food elimination diet (SFED), also termed a GI hypoallergenic diet, was used to empirically treat patients with EoE including adults. The 6 foods eliminated are ingestion of milk, soy, egg, wheat, peanuts/tree nuts, and shellfish/fish. A 74-78 \% response was noted in improved esophageal inflammation, as well as improved symptoms in both children and adults who underwent the SFED therapy $[76,78]$. In a retrospective review of 31 patients there was no significant difference in patients who received either targeted elimination or empiric elimination diet for EoE, although there was a trend 
for better response in the empiric diet elimination group [79] Due to unpredictable results and high cost of skin testing, we prefer to use an empiric GI hypoallergenic diet in our patients with EoE. Food re-introduction can be done in a stepwise fashion. Repeat endoscopies are required when the food groups are reintroduced after 4-6 weeks to determine esophageal eosinophil count [80]. The most common foods associated with EoE based on re-introduction were wheat ( $60 \%$ of cases) and milk ( $50 \%$ of cases) [76]. Foods that cause recurrence of EoE symptoms should be eliminated indefinitely.

\section{Esophageal dilation}

The development of esophageal strictures is a major concern in patients with EoE. A delay in diagnosis and treatment has been associated with fibrotic features and strictures. A 0-2 year delay in diagnosis of EoE had a prevalence of $17 \%$ strictures, while those diagnosed $>20$ years after symptom onset had a $71 \%$ prevalence of strictures $(\mathrm{P}<.001)$ [81]. In a recent retrospective study of 379 patients, the likelihood of fibrostenotic disease, characterized if there were esophageal rings, narrowing, or strictures, increased markedly with age. The study showed that for every 10 -year increase in age the odds of fibrostenotic disease more than doubled. This suggests that the natural history of EoE progresses from an inflammatory to a fibrostenotic disease [82]. Previous studies reported an increase risk of perforation in EoE patients undergoing endoscopy with or without dilation of the esophagus. Recommendations for dilation were initially to treat for 8 weeks before considering dilation [83-86]. However, later studies and our own experience showed the risk of perforation with dilation was much less. Also the type of dilators and number of prior dilations were not associated with complications, regardless of age $[87,88]$.

\section{Maintenance of therapy}

Since EoE is a chronic disease, relapse of symptoms after treatment cessation ranges from $45 \%-79 \%[32,51]$. In a study by Straumann et al in 2011, patients given low-dose budesonide (swallowed budesonide $0.25 \mathrm{mg}$ twice a day) compared to placebo showed more effective maintenance of histologic and clinical remission. Maintenance of complete histologic remission ( $<5$ mean eos/HPF) was seen in $35.7 \%$ of patients receiving lowdose budesonide and partial remission (5-20 mean eos/HPF) was seen in $14.3 \%$ of patients during a 50 -week period. None of the placebo group achieved complete remission [89]. In a study by Levine et al in 2012, children with EoE who were maintained on PPI alone (no use of steroids) for a duration of $3.0 \pm 2.4$ years showed significant improvement in symptoms, however there was poor histologic response [90]. In a recent study, Kuchen et al assessed risks of food impaction in 206 patients with EoE over a median period of 5 years. Treatment with swallowed topical corticosteroids was shown to be protective against food impaction in this group (OR 0.411, 95\% CI: 0.203-0.835, P = 0.014) [91]. Regarding efficacy of food elimination in maintenance therapy, a study by Lucendo et al found that patients who continued to avoid offending foods in an elimination diet were found to maintain histopathologic and clinical EoE remission for up to 3 years [92]. Current guidelines recommend considering long-term topical steroids and /or dietary restriction in all patients, especially patients with severe dysphagia, food impaction, esophageal stricture, and rapid symptomatic / histologic relapse following initial therapy [4].

\section{Conclusion}

EoE is a chronic immune/antigen-mediated disease with an increasing prevalence in both children and adults. Early diagnosis and treatment is needed to avoid the progressive course from inflammation to fibrostenotic disease. Symptoms of esophageal dysfunction, esophageal biopsies usually with > 15 eos/HPF and exclusion of other causes of esophageal eosinophilia is the mainstay of diagnosis. Treatment involves PPI therapy, swallowed inhaled steroids or viscous budesonide, elimination of dietary triggers, and esophageal dilation as needed. Maintenance of therapy is controversial, however relapse rate is high and continued therapy with diet elimination and/or steroids may be warranted in advanced cases with EoE. Further studies are needed for patients with refractory EoE, targeted drug therapy, long term maintenance therapy, and outcome of the these patients over time.

\section{Source of support}

Ertan Research and Educational Foundation, Memorial Hermann System, Houston, Texas.

\section{References}

1. Liacouras CA, Furuta GT, Hirano I, Atkins D, Attwood SE, Bonis PA, et al. Eosinophilic esophagitis: updated consensus recommendations for children and adults. J Allergy Clin Immunol. 2011;128:21477849. doi:10.1016/j.jaci.2011.02.040.

2. Rodrigo S, Abboud G, Oh D, DeMeester SR, Hagen J, Lipham J, et al. High intraepithelial eosinophil counts in esophageal squamous epithelium are not specific for eosinophilic esophagitis in adults. Am J Gastroenterol. 2008;103:18289205. doi:10.1111/j.15720241.2007.01594.x.

3. Molina-Infante J, Ferrando-Lamana L, Ripoll C, Hernandez-Alonso M, Mateos JM, Fernandez-Bermejo M, et al. Esophageal eosinophilic infiltration responds to proton pump inhibition in most adults. Clin Gastroenterol Hepatol. 2011;9:20920599. doi:10.1016/j. cgh.2010.09.019.

4. Dellon ES, Gonsalves N, Hirano I, Furuta GT, Liacouras CA, Katzka DA, et al. ACG clinical guideline: Evidenced based approach to the diagnosis and management of esophageal eosinophilia and eosinophilic esophagitis (EoE). Am J Gastroenterol. 2013;108:23567357. doi:10.1038/ajg.2013.71.

5. Landres RT, Kuster GG, Strum WB. Eosinophilic esophagitis in a patient with vigorous achalasia. Gastroenterology. 1978;74:648822.

6. Attwood SE, Smyrk TC, Demeester TR, Jones JB. Esophageal eosinophilia with dysphagia. A distinct clinicopathologic syndrome. Dig Dis Sci. 1993;38:8420741.

7. Kelly KJ, Lazenby AJ, Rowe PC, Yardley JH, Perman JA, Sampson HA. Eosinophilic esophagitis attributed to gastroesophageal reflux: 
improvement with an amino acid-based formula. Gastroenterology. 1995;109:7557132.

8. Fox VL, Nurko S, Furuta GT. Eosinophilic esophagitis: it's not just kid's stuff. Gastrointest Endosc. 2002;56:12145607.

9. Gill R, Durst P, Rewalt M, Elitsur Y. Eosinophilic esophagitis disease in children from West Virginia: a review of the last decade (19952004). Am J Gastroenterol. 2007;102:17573789. doi:10.1111/j.15720241.2007.01352.x.

10. Cherian S, Smith NM, Forbes DA. Rapidly increasing prevalence of eosinophilic oesophagitis in Western Australia. Arch Dis Child. 2006 Dec;91(12):1000-4.

11. Noel RJ, Putnam PE, Rothenberg ME. Eosinophilic esophagitis. N Engl J Med. 2004 Aug 26;351(9):940-1.

12. Prasad GA, Alexander JA, Schleck CD, Zinsmeister AR, Smyrk TC, Elias RM, et al. Epidemiology of eosinophilic esophagitis over three decades in Olmsted County, Minnesota. Clin Gastroenterol Hepatol. 2009;7:19577011. doi:10.1016/j.cgh.2009.06.023.

13. Hruz P, Straumann A, Bussmann C, Heer P, Simon H-U, Zwahlen M, et al. Escalating incidence of eosinophilic esophagitis: a 20-year prospective, population-based study in Olten County, Switzerland. J Allergy Clin Immunol. 2011;128:22019091. doi:10.1016/j. jaci.2011.09.013.

14. Ally MR, Maydonovitch CL, Betteridge JD, Veerappan GR, Moawad FJ. Prevalence of eosinophilic esophagitis in a United States military health-care population. Dis Esophagus. 2014:24827543. doi:10.1111/ dote.12229.

15. Dellon ES, Jensen ET, Martin CF, Shaheen NJ, Kappelman MD. Prevalence of eosinophilic esophagitis in the United States. Clin Gastroenterol Hepatol. 2014;12:24035773. doi:10.1016/j.cgh.2013.09.008.

16. Gawron AJ, Hirano I. Eosinophilic esophagitis--emerging epidemic or misdiagnosed malady? Clin Gastroenterol Hepatol. 2014;12:24216469. doi:10.1016/j.cgh.2013.10.036.

17. Moawad FJ, Veerappan GR, Lake JM, Maydonovitch CL, Haymore BR, Kosisky SE, et al. Correlation between eosinophilic oesophagitis and aeroallergens. Aliment Pharmacol Ther. 2010;31:19925501. doi:10.1111/j.1365-2036.2009.04199.x.

18. Almansa C, Krishna M, Buchner AM, Ghabril MS, Talley N, DeVault KR, et al. Seasonal distribution in newly diagnosed cases of eosinophilic esophagitis in adults. Am J Gastroenterol. 2009;104:19240704. doi:10.1038/ajg.2008.169.

19. Elitsur Y, Aswani R, Lund V, Dementieva Y. Seasonal distribution and eosinophilic esophagitis: the experience in children living in rural communities. J Clin Gastroenterol. 2013;47:23164688. doi:10.1097/ MCG.0b013e31826df861.

20. Elias MK, Kopacova J, Arora AS, Dierkhising RA, Enders FT, Katzka DA, et al. The Diagnosis of Esophageal Eosinophilia is Not Increased in the Summer Months. Dysphagia. 2015;30:25288197. doi:10.1007/ s00455-014-9574-1.

21. Aceves SS. Eosinophilic esophagitis. Immunol Allergy Clin North Am. 2015;35:25459582. doi:10.1016/j.iac.2014.09.007.

22. Blanchard C, Wang N, Stringer KF, Mishra A, Fulkerson PC, Abonia $\mathrm{JP}$, et al. Eotaxin-3 and a uniquely conserved gene-expression profile in eosinophilic esophagitis. J Clin Invest. 2006;116:16453027. doi:10.1172/JCI26679.
23. Dellon ES. The pathogenesis of eosinophilic esophagitis: beyond the eosinophil. Dig Dis Sci. 2013;58:23625288. doi:10.1007/s10620-0132679-9.

24.Cheng E, Souza RF, Spechler SJ. Tissue remodeling in eosinophilic esophagitis. Am J Physiol Gastrointest Liver Physiol. 2012;303:23019192. doi:10.1152/ajpgi.00313.2012.

25.Sperry SL, Woosley JT, Shaheen NJ, Dellon ES. Influence of race and gender on the presentation of eosinophilic esophagitis. Am J Gastroenterol. 2012;107:21971538. doi:10.1038/ajg.2011.342.

26. Mukkada VA, Haas A, Maune NC, Capocelli KE, Henry M, Gilman N, et al. Feeding Dysfunction in Children With Eosinophilic Gastrointestinal Diseases. Pediatrics. 2010;126:20696733. doi:10.1542/peds.20092227.

27. Haas AM, Maune NC. Clinical presentation of feeding dysfunction in children with eosinophilic gastrointestinal disease. Immunol Allergy Clin North Am. 2009;29:19141342. doi:10.1016/j.iac.2008.09.014.

28. Kapel RC, Miller JK, Torres C, Aksoy S, Lash R, Katzka DA. Eosinophilic esophagitis: a prevalent disease in the United States that affects all age groups. Gastroenterology. 2008;134:18471509. doi:10.1053/j. gastro.2008.02.016.

29. Markowitz JE, Spergel JM, Ruchelli E, Liacouras CA. Elemental diet is an effective treatment for eosinophilic esophagitis in children and adolescents. Am J Gastroenterol. 2003;98:12738455. doi:10.1111/ j.1572-0241.2003.07390.x.

30. Sperry SLW, Crockett SD, Miller CB, Shaheen NJ, Dellon ES. Esophageal foreign-body impactions: epidemiology, time trends, and the impact of the increasing prevalence of eosinophilic esophagitis. Gastrointest Endosc. 2011;74:21889135. doi:10.1016/j.gie.2011.06.029.

31. Remedios M, Campbell C, Jones DM, Kerlin P. Eosinophilic esophagitis in adults: clinical, endoscopic, histologic findings, and response to treatment with fluticasone propionate. Gastrointest Endosc. 2006;63:16377308. doi:10.1016/j.gie.2005.07.049.

32. Assa'ad AH, Putnam PE, Collins MH, Akers RM, Jameson SC, Kirby $\mathrm{CL}$, et al. Pediatric patients with eosinophilic esophagitis: an 8-year follow-up. J Allergy Clin Immunol. 2007;119:17258309. doi:10.1016/j. jaci.2006.10.044.

33. Baxi S, Gupta SK, Swigonski N, Fitzgerald JF. Clinical presentation of patients with eosinophilic inflammation of the esophagus. Gastrointest Endosc. 2006;64:16996334. doi:10.1016/j.gie.2006.03.931.

34. Sgouros SN, Bergele C, Mantides A. Eosinophilic esophagitis in adults: a systematic review. Eur J Gastroenterol Hepatol. 2006;18:16394804.

35. Dellon ES, Liacouras CA. Advances in clinical management of eosinophilic esophagitis. Gastroenterology. 2014;147:25109885. doi:10.1053/j.gastro.2014.07.055.

36. Peery AF, Cao H, Dominik R, Shaheen NJ, Dellon ES. Variable reliability of endoscopic findings with white-light and narrow-band imaging for patients with suspected eosinophilic esophagitis. Clin Gastroenterol Hepatol. 2011;9:21377547. doi:10.1016/j.cgh.2011.02.026.

37. Hirano I, Moy N, Heckman MG, Thomas CS, Gonsalves N, Achem SR. Endoscopic assessment of the oesophageal features of eosinophilic oesophagitis: validation of a novel classification and grading system. Gut. 2013;62:22619364. doi:10.1136/gutjnl-2011-301817.

38. Dellon ES, Aderoju A, Woosley JT, Sandler RS, Shaheen NJ. Variability in diagnostic criteria for eosinophilic esophagitis: a systematic review. 
Am J Gastroenterol. 2007;102:17617209. doi:10.1111/j.15720241.2007.01396.x.

39. Kim HP, Vance RB, Shaheen NJ, Dellon ES. The prevalence and diagnostic utility of endoscopic features of eosinophilic esophagitis: a meta-analysis. Clin Gastroenterol Hepatol. 2012;10:22610003. doi:10.1016/j.cgh.2012.04.019.

40.Gonsalves N, Policarpio-Nicolas M, Zhang Q, Rao MS, Hirano I. Histopathologic variability and endoscopic correlates in adults with eosinophilic esophagitis. Gastrointest Endosc. 2006;64:16923475. doi:10.1016/j.gie.2006.04.037.

41. Sperry SLW, Shaheen NJ, Dellon ES. Toward uniformity in the diagnosis of eosinophilic esophagitis (EoE): the effect of guidelines on variability of diagnostic criteria for EoE. Am J Gastroenterol. 2011;106:21304500. doi:10.1038/ajg.2011.10.

42. Dellon ES, Fritchie KJ, Rubinas TC, Woosley JT, Shaheen NJ. Interand intraobserver reliability and validation of a new method for determination of eosinophil counts in patients with esophageal eosinophilia. Dig Dis Sci. 2010;55:19830560. doi:10.1007/s10620009-1005-z.

43. Enns R, Kazemi P, Chung W, Lee M. Eosinophilic esophagitis: Clinical features, endoscopic findings and response to treatment. Can J Gastroenterol. 2010;24:21152459.

44.Villa N, El-Serag HB, Younes M, Ertan A. Esophageal eosinophilia after radiofrequency ablation for Barrett's esophagus. Dis Esophagus. 2013;26:23384233. doi:10.1111/dote.12033.

45. Sayej WN, Patel R, Baker RD, Tron E, Baker SS. Treatment with high-dose proton pump inhibitors helps distinguish eosinophilic esophagitis from noneosinophilic esophagitis. J Pediatr Gastroenterol Nutr. 2009;49:19633574. doi:10.1097/MPG.0b013e31819c4b3e.

46. Dranove JE, Horn DS, Davis MA, Kernek KM, Gupta SK. Predictors of response to proton pump inhibitor therapy among children with significant esophageal eosinophilia. J Pediatr. 2009;154:18783791. doi:10.1016/j.jpeds.2008.07.042.

47. Krarup AL, Villadsen GE, Mejlgaard E, Olesen SS, Drewes AM, Funch-Jensen P. Acid hypersensitivity in patients with eosinophilic oesophagitis. Scand J Gastroenterol. 2010;45:20001646. doi:10.3109/00365520903469931.

48. Peterson KA, Thomas KL, Hilden K, Emerson LL, Wills JC, Fang JC. Comparison of esomeprazole to aerosolized, swallowed fluticasone for eosinophilic esophagitis. Dig Dis Sci. 2010;55:19533356. doi:10.1007/s10620-009-0859-4.

49. Vitellas KM, Bennett WF, Bova JG, Johnston JC, Caldwell JH, Mayle JE Idiopathic eosinophilic esophagitis. Radiology. 1993;186:8430189. doi:10.1148/radiology.186.3.8430189.

50. Liacouras CA, Wenner WJ, Brown K, Ruchelli E. Primary eosinophilic esophagitis in children: successful treatment with oral corticosteroids. J Pediatr Gastroenterol Nutr. 1998;26:9552132.

51.Schaefer ET, Fitzgerald JF, Molleston JP, Croffie JM, Pfefferkorn MD, Corkins MR, et al. Comparison of oral prednisone and topical fluticasone in the treatment of eosinophilic esophagitis: a randomized trial in children. Clin Gastroenterol Hepatol. 2008;6:18237866. doi:10.1016/j.cgh.2007.11.008.

52. Faubion WA, Perrault J, Burgart LJ, Zein NN, Clawson M, Freese DK. Treatment of eosinophilic esophagitis with inhaled corticosteroids. J Pediatr Gastroenterol Nutr. 1998;27:9669733.
53.Teitelbaum JE, Fox VL, Twarog FJ, Nurko S, Antonioli D, Gleich G, et al. Eosinophilic esophagitis in children: immunopathological analysis and response to fluticasone propionate. Gastroenterology. 2002;122:11984507.

54. Konikoff MR, Noel RJ, Blanchard C, Kirby C, Jameson SC, Buckmeier BK, et al. A randomized, double-blind, placebo-controlled trial of fluticasone propionate for pediatric eosinophilic esophagitis. Gastroenterology. 2006;131:17101314. doi:10.1053/j.gastro.2006.08.033.

55. Arora AS, Perrault J, Smyrk TC. Topical corticosteroid treatment of dysphagia due to eosinophilic esophagitis in adults. Mayo Clin Proc. 2003;78:12839078. doi:10.4065/78.7.830.

56. Lucendo AJ, Pascual-Turrión JM, Navarro M, Comas C, Castillo P, Letrán A, et al. Endoscopic, bioptic, and manometric findings in eosinophilic esophagitis before and after steroid therapy: a case series. Endoscopy. 2007;39:17703383. doi:10.1055/s-2007-966738.

57. Alexander JA, Jung KW, Arora AS, Enders F, Katzka DA, Kephardt GM, et al. Swallowed fluticasone improves histologic but not symptomatic response of adults with eosinophilic esophagitis. Clin Gastroenterol Hepatol. 2012;10:22475741. doi:10.1016/j.cgh.2012.03.018.

58. Butz BK, Wen T, Gleich GJ, Furuta GT, Spergel J, King E, et al. Efficacy, dose reduction, and resistance to high-dose fluticasone in patients with eosinophilic esophagitis. Gastroenterology. 2014;147:24768678. doi:10.1053/j.gastro.2014.04.019.

59. Aceves SS, Dohil R, Newbury RO, Bastian JF. Topical viscous budesonide suspension for treatment of eosinophilic esophagitis. J Allergy Clin Immunol. 2005;116:16159647. doi:10.1016/j.jaci.2005.05.011.

60. Aceves SS, Bastian JF, Newbury RO, Dohil R. Oral viscous budesonide: a potential new therapy for eosinophilic esophagitis in children. Am J Gastroenterol. 2007;102:17581266. doi:10.1111/j.15720241.2007.01379.x.

61. Straumann A, Conus S, Degen L, Felder S, Kummer M, Engel H, et al. Budesonide is effective in adolescent and adult patients with active eosinophilic esophagitis. Gastroenterology. 2010;139:20682320. doi:10.1053/j.gastro.2010.07.048.

62. Dohil R, Newbury R, Fox L, Bastian J, Aceves S. Oral viscous budesonide is effective in children with eosinophilic esophagitis in a randomized, placebo-controlled trial. Gastroenterology. 2010;139:20457157. doi:10.1053/j.gastro.2010.05.001.

63. Dellon ES, Sheikh A, Speck O, Woodward K, Whitlow AB, Hores $J M$, et al. Viscous topical is more effective than nebulized steroid therapy for patients with eosinophilic esophagitis. Gastroenterology. 2012;143:22561055. doi:10.1053/j.gastro.2012.04.049.

64. Stein ML, Collins MH, Villanueva JM, Kushner JP, Putnam PE, Buckmeier BK, et al. Anti-IL-5 (mepolizumab) therapy for eosinophilic esophagitis. J Allergy Clin Immunol. 2006;118:17157662. doi:10.1016/j.jaci.2006.09.007.

65. Straumann A, Conus S, Grzonka P, Kita H, Kephart G, Bussmann C, et al. Anti-interleukin-5 antibody treatment (mepolizumab) in active eosinophilic oesophagitis: a randomised, placebo-controlled, doubleblind trial. Gut. 2010;59:19828470. doi:10.1136/gut.2009.178558.

66. Assa'ad AH, Gupta SK, Collins MH, Thomson M, Heath AT, Smith DA, et al. An antibody against IL-5 reduces numbers of esophageal intraepithelial eosinophils in children with eosinophilic esophagitis. Gastroenterology. 2011;141:21835135. doi:10.1053/j. gastro.2011.07.044 
67. Spergel JM, Rothenberg ME, Collins MH, Furuta GT, Markowitz JE, Fuchs G, et al. Reslizumab in children and adolescents with eosinophilic esophagitis: results of a double-blind, randomized, placebo-controlled trial. J Allergy Clin Immunol. 2012;129:22206777. doi:10.1016/j.jaci.2011.11.044.

68. Rocha R, Vitor AB, Trindade E, Lima R, Tavares $\mathrm{M}$, Lopes J, et al Omalizumab in the treatment of eosinophilic esophagitis and food allergy. Eur J Pediatr. 2011;170:21809010. doi:10.1007/s00431-0111540-4.

69. Fang JC, Hilden K, Gleich GJ, Emerson LL, Ogorman MA, Lowichik A, et al. A Pilot Study of the Treatment of Eosinophilic Esophagitis With Omalizumab. Gastroenterology. 2011;140. doi:10.1016/S00165085(11)60951-7.

70.Straumann A, Bauer M, Fischer B, Blaser K, Simon HU. Idiopathic eosinophilic esophagitis is associated with a $\mathrm{T}(\mathrm{H}) 2$-type allergic inflammatory response. J Allergy Clin Immunol. 2001;108:11742273. doi:10.1067/mai.2001.119917.

71. Straumann A, Bussmann C, Conus S, Beglinger C, Simon H-U. Anti-TNFalpha (infliximab) therapy for severe adult eosinophilic esophagitis. J Allergy Clin Immunol. 2008;122:18678345. doi:10.1016/j. jaci.2008.06.012.

72. Netzer P, Gschossmann JM, Straumann A, Sendensky A, Weimann R, Schoepfer AM. Corticosteroid-dependent eosinophilic oesophagitis: azathioprine and 6-mercaptopurine can induce and maintain longterm remission. Eur J Gastroenterol Hepatol. 2007;19:17873610. doi:10.1097/MEG.0b013e32825a6ab4.

73. Henderson CJ, Abonia JP, King EC, Putnam PE, Collins MH, Franciosi $J P$, et al. Comparative dietary therapy effectiveness in remission of pediatric eosinophilic esophagitis. J Allergy Clin Immunol. 2012;129:22541246. doi:10.1016/j.jaci.2012.03.023.

74. Arias A, González-Cervera J, Tenias JM, Lucendo AJ. Efficacy of dietary interventions for inducing histologic remission in patients with eosinophilic esophagitis: a systematic review and metaanalysis. Gastroenterology. 2014;146:24534634. doi:10.1053/j. gastro.2014.02.006.

75. Spergel JM, Andrews T, Brown-Whitehorn TF, Beausoleil JL, Liacouras CA. Treatment of eosinophilic esophagitis with specific food elimination diet directed by a combination of skin prick and patch tests. Ann Allergy Asthma Immunol. 2005;95:16279563. doi:10.1016/ S1081-1206(10)61151-9.

76. Gonsalves N, Yang G-Y, Doerfler B, Ritz S, Ditto AM, Hirano I. Elimination diet effectively treats eosinophilic esophagitis in adults; food reintroduction identifies causative factors. Gastroenterology. 2012;142:22391333. doi:10.1053/j.gastro.2012.03.001.

77. Aceves SS. Food allergy testing in eosinophilic esophagitis: what the gastroenterologist needs to know. Clin Gastroenterol Hepatol. 2014;12:24035776. doi:10.1016/j.cgh.2013.09.007.

78. Kagalwalla AF, Sentongo TA, Ritz S, Hess T, Nelson SP, Emerick KM, et al. Effect of six-food elimination diet on clinical and histologic outcomes in eosinophilic esophagitis. Clin Gastroenterol Hepatol. 2006;4:16860614. doi:10.1016/j.cgh.2006.05.026.

79. Wolf WA, Jerath MR, Sperry SLW, Shaheen NJ, Dellon ES. Dietary elimination therapy is an effective option for adults with eosinophilic esophagitis. Clin Gastroenterol Hepatol. 2014;12:24440337. doi:10.1016/j.cgh.2013.12.034

80. Doerfler B, Bryce P, Hirano I, Gonsalves N. Practical approach to implementing dietary therapy in adults with eosinophilic esophagitis: the Chicago experience. Dis Esophagus. 2015;28:24602224. doi:10.1111/dote.12175.

81. Schoepfer AM, Safroneeva E, Bussmann C, Kuchen T, Portmann S, Simon $\mathrm{H}-\mathrm{U}$, et al. Delay in diagnosis of eosinophilic esophagitis increases risk for stricture formation in a time-dependent manner. Gastroenterology. 2013;145:23954315. doi:10.1053/j.gastro.2013.08.015.

82. Dellon ES, Kim HP, Sperry SLW, Rybnicek DA, Woosley JT, Shaheen NJ. A phenotypic analysis shows that eosinophilic esophagitis is a progressive fibrostenotic disease. Gastrointest Endosc. 2014;79:24275329. doi:10.1016/j.gie.2013.10.027.

83. Kaplan M, Mutlu EA, Jakate S, Bruninga K, Losurdo J, Losurdo J, et al. Endoscopy in eosinophilic esophagitis: "feline" esophagus and perforation risk. Clin Gastroenterol Hepatol. 2003;1:15017642.

84. Cohen MS, Kaufman AB, Palazzo JP, Nevin D, Dimarino AJ, Cohen S. An audit of endoscopic complications in adult eosinophilic esophagitis. Clin Gastroenterol Hepatol. 2007;5:17683993. doi:10.1016/j. cgh.2007.05.017

85. Eisenbach C, Merle U, Schirmacher P, Hansmann J, Stiehl A, Stremmel W, et al. Perforation of the esophagus after dilation treatment for dysphagia in a patient with eosinophilic esophagitis. Endoscopy. 2006;38 Suppl 2:17123211. doi:10.1055/s-2006-944676.

86. Straumann A, Bussmann C, Zuber M, Vannini S, Simon H-U, Schoepfer A. Eosinophilic esophagitis: analysis of food impaction and perforation in 251 adolescent and adult patients. Clin Gastroenterol Hepatol. 2008;6:18407800. doi:10.1016/j.cgh.2008.02.003.

87. Dellon ES, Gibbs WB, Rubinas TC, Fritchie KJ, Madanick RD, Woosley JT, et al. Esophageal dilation in eosinophilic esophagitis: safety and predictors of clinical response and complications. Gastrointest Endosc. 2010;71:20170913. doi:10.1016/j.gie.2009.10.047.

88. Ally MR, Dias J, Veerappan GR, Maydonovitch CL, Wong RK, Moawad FJ. Safety of dilation in adults with eosinophilic esophagitis. Dis Esophagus. 2013;26:22676406. doi:10.1111/j.1442-2050.2012.01363.x.

89. Straumann A, Conus S, Degen L, Frei C, Bussmann C, Beglinger C, et al. Long-term budesonide maintenance treatment is partially effective for patients with eosinophilic esophagitis. Clin Gastroenterol Hepatol. 2011;9:21277394. doi:10.1016/j.cgh.2011.01.017.

90. Levine J, Lai J, Edelman M, Schuval SJ. Conservative long-term treatment of children with eosinophilic esophagitis. Ann Allergy Asthma Immunol. 2012;108:22541409. doi:10.1016/j.anai.2012.02.024.

91. Kuchen T, Straumann A, Safroneeva E, Romero Y, Bussmann C, Vavricka $S$, et al. Swallowed topical corticosteroids reduce the risk for long-lasting bolus impactions in eosinophilic esophagitis. Allergy. 2014;69:24894658. doi:10.1111/all.12455.

92. Lucendo AJ, Arias Á, González-Cervera J, Yagüe-Compadre JL, Guagnozzi D, Angueira T, et al. Empiric 6-food elimination diet induced and maintained prolonged remission in patients with adult eosinophilic esophagitis: a prospective study on the food cause of the disease. J Allergy Clin Immunol. 2013;131:23375693. doi:10.1016/j. jaci.2012.12.664. 